\title{
Erratum to: Refinements in mathematics undergraduate students' reasoning on completed infinite iterative processes
}

\author{
Iuliana Radu • Keith Weber
}

Published online: 9 June 2011

(C) Springer Science+Business Media B.V. 2011

\section{Erratum to: Educ Stud Math \\ DOI 10.1007/s10649-011-9318-1}

The original version of this article unfortunately contained a mistake. The presentation of Figure 1 was incorrect. The legend from Figure 1 is missing. The corrected figure is given below.

The online version of the original article can be found at http://dx.doi.org/10.1007/s10649-011-9318-1.

\section{Radu $(\bowtie)$}

Center for Mathematics, Science, and Computer Education, Rutgers University, 118 Frelinghuysen Road, Piscataway NJ 08854, USA

e-mail: tenis@rci.rutgers.edu

K. Weber

Graduate School of Education, Rutgers University, 10 Seminary Place, New Brunswick NJ 08901, USA e-mail: keith.weber@gse.rutgers.edu 


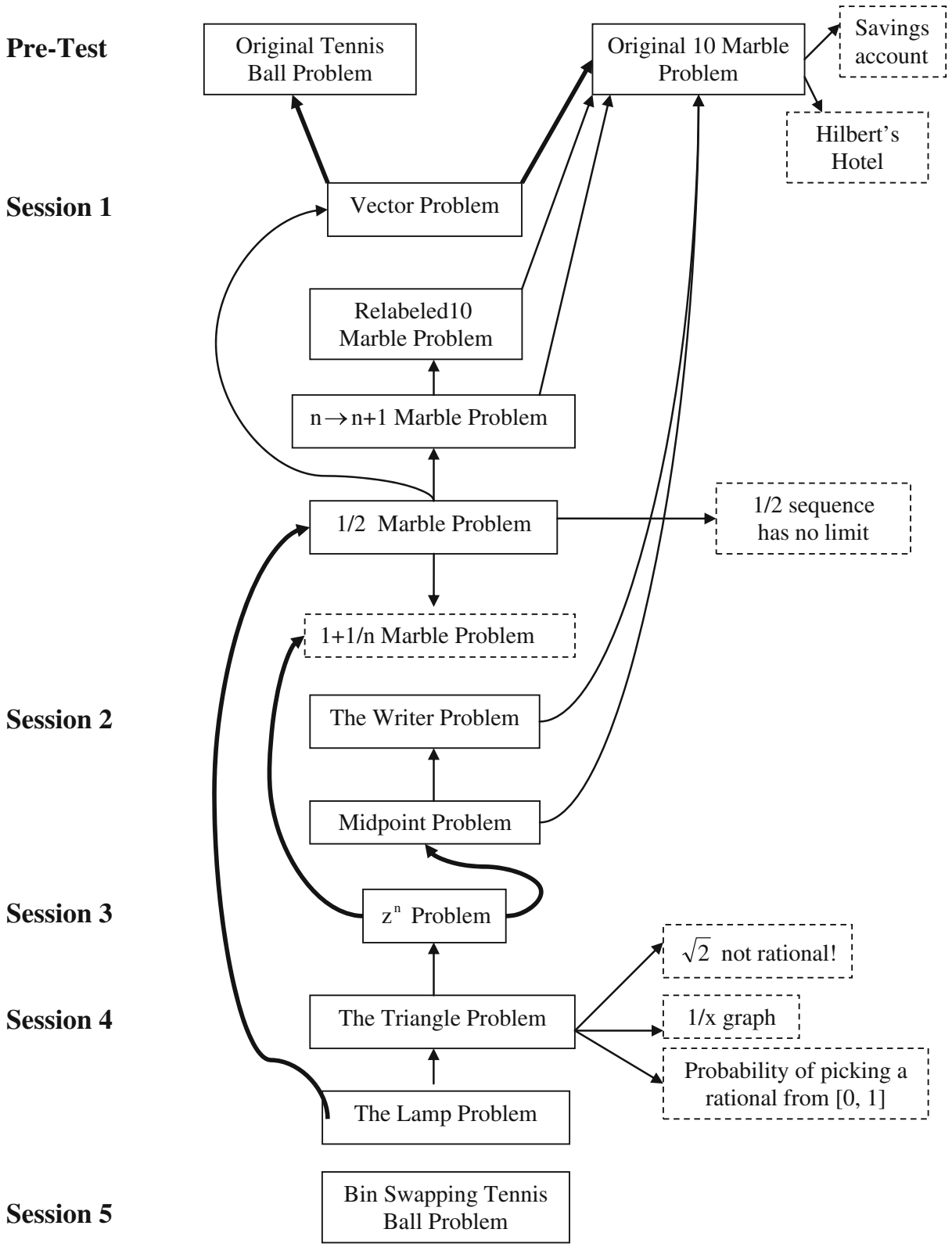

\section{Legend}

$x \rightarrow y:$ While discussing $\mathrm{x}$, problem $\mathrm{y}$ was referenced

Bold arrow: the reference caused one or both of the students to change their solution to the referenced problem

Dashed line box: the problem in the box was proposed by one of the students

Fig. 1 Student references across tasks 